\title{
Baseline medication adherence and response to an electronically delivered health literacy intervention targeting adherence
}

This article was published in the following Dove Press journal:

Neurobehavioral HIV Medicine

17 October 2012

Number of times this article has been viewed

\author{
Raymond L Ownby' \\ Drenna Waldrop-Valverde ${ }^{2}$ \\ Joshua Caballero 3 \\ Robin J Jacobs' \\ 'Department of Psychiatry \\ and Behavioral Medicine, Nova \\ Southeastern University, Fort \\ Lauderdale, FL, ${ }^{2}$ Nell Hodgson \\ Woodruff School of Nursing, \\ Emory University, Atlanta, GA, \\ ${ }^{3}$ Department of Pharmacy Practice, \\ Nova Southeastern University, Fort \\ Lauderdale, FL, USA
}

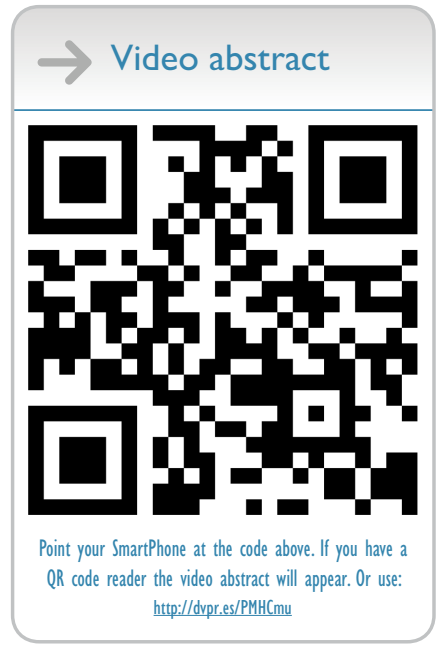

Correspondence: Raymond L Ownby Room 1477, Nova Southeastern University, 3200 South University Drive, Fort Lauderdale, FL 33328, USA

Tel + | 954262 |48|

Emailro7I@nova.edu

\begin{abstract}
Medication adherence in persons treated for human immunodeficiency virus (HIV) continues to be an important focus for intervention. While high levels of adherence are required for good clinical outcomes, research shows many patients do not achieve these levels. Despite multiple interventions to improve adherence, most require multiple sessions delivered by trained clinicians. Cost and lack of trained personnel limit the availability of these interventions. Alternatives to clinician-delivered interventions are interventions provided via electronic devices (eg, personal/tablet computers and smartphones). Modern technology allows devices to provide tailoring of content to patient characteristics and learning needs, and to be excellent platforms to deliver multimedia teaching content. The intervention reported drew on research on health literacy in persons with HIV and the relation of health literacy to medication adherence in persons treated for HIV to develop an electronically delivered application. Using the Information-Motivation-Behavioral Skills model as a conceptual framework for understanding patients' information needs, a computer-delivered intervention was developed, its usability and acceptability was assessed, and medication adherence in 118 patients for 1 month before and after they completed the intervention was evaluated. Changes in participant adherence were evaluated in sequential models with progressively lower levels of baseline medication adherence. Results show that although changes in adherence in the entire sample only approached statistical significance, individuals with adherence less than $95 \%$ showed significant increases in adherence over time. Participants' self-reported knowledge and behavioral skills increased over the course of the study. Their change in information predicted their post-intervention adherence, suggesting a link between the intervention's effects and outcomes. A computer-delivered intervention targeting HIV-related health literacy may thus be a useful strategy for improving patient adherence.
\end{abstract}

Keywords: health literacy, medication adherence, cognition

\section{Introduction}

Human immunodeficiency virus (HIV) infection can be effectively treated with combination antiretroviral therapy, but successful treatment requires that patients maintain high levels of adherence to their medications. Required levels of adherence are at least $80 \%-90 \%$ (and perhaps much higher), ${ }^{1-3}$ but the typical average level of adherence in many studies has been much lower in the range of 50\%-60\%., High levels of adherence are important for several reasons. First, medication adherence is associated with clinical outcomes. ${ }^{6,7}$ In addition, several studies have shown that individuals with low levels of virus, often obtained with good adherence, are less likely to transmit HIV to other persons. ${ }^{8}$ Medication adherence is therefore important not only for patients' 
health but also for public health, and new interventions to improve patient adherence are important.

Theories of health behavior have been used to develop interventions to promote adherence, and many have been successful. Theories such as the Information-MotivationBehavioral Skills (IMB) model, ${ }^{9}$ the Health Belief Model, ${ }^{10}$ and the Theory of Planned Behavior, ${ }^{11}$ as well as empirical research on factors associated with poor adherence, have been the basis for various effective interventions. ${ }^{12,13}$ These interventions have usually targeted individuals' beliefs or knowledge about the disease or its treatment based on the core idea that if patients understand the importance of adherence and the consequences of nonadherence they will be more likely to take their medications regularly. Other interventions also focus on barriers to adherence, such as substance abuse or depression, or on specific adherence-related skills. ${ }^{13,14}$

Effective evidence-based interventions exist but are not always available to those who need them. Successful interventions often involve multiple elements such as patient education, reminders, and changes in dosing schedule or format, and require significant clinician (physician, nurse, pharmacist, and other health care provider) time. ${ }^{15}$ Although clearly an important role for those focused on saving patients' lives by improving their adherence to critically important medications, some tasks are likely repetitive and don't require highly skilled clinicians. One strategy that might reduce the burden of providing adherence interventions is to create ways in which they can be delivered using electronic technologies. Although initially more expensive to develop, electronic interventions can be delivered to patients at low cost and with little clinician input on existing computers or over the Internet on mobile devices. While they are not as flexible as those delivered by trained clinicians, electronic interventions may be able to deliver similar intervention content. By doing so, busy clinicians may be released from routine educational duties to cope with more complex problems that demand their attention. These interventions would not replace clinicians but reduce the demands on their time made by routine tasks and allow them to provide critically important support to patients.

An important factor in patients' medication adherence that could be addressed in an electronic intervention is patient level of health literacy. Health literacy has been shown in multiple studies to be an important factor in individuals treated for HIV. Kalichman and Rompa, for example, found that low levels of health literacy correlated with lower CD4 cell counts, higher viral loads, and number of hospitalizations. ${ }^{16}$ In another study, Kalichman et al showed that patients with lower health literacy had less knowledge about HIV and its treatment. ${ }^{17}$ Finally, poor health literacy also is related to lower levels of medication adherence in patients with HIV. ${ }^{18}$ These findings show that health literacy might be a likely target for an intervention to improve patient medication adherence.

Health literacy has been defined as "the degree to which individuals have the capacity to obtain, process, and understand basic health information and services needed to make appropriate health decisions." ${ }^{19}$ This definition is broad and doesn't readily lead to a strategy for improving patients' health literacy. A theory of health behavior that has already been used to develop interventions to improve medication adherence in persons with HIV is the IMB model. ${ }^{9}$ It specifies that HIV-related health behaviors depend on the degree to which individuals have information about their condition and its treatment and the behavioral skills needed to perform related behaviors (eg, remembering to take medications). These elements are thought to contribute to individuals' motivation to take their medications. Since information and content about behavioral skills can readily be provided in an electronic format, the IMB model is a useful framework to organize content provided by an electronic intervention. While detailed interventions focused on changing patients' beliefs, attitudes, and skills are likely to still be needed in order for them to achieve optimal levels of adherence, basic information leading to changes in adherence behaviors can be provided and reinforced in an automated intervention. The purpose of this study was thus to evaluate the extent to which an electronic intervention targeting health literacy and organized by the elements of the IMB model could improve patients' health literacy and medication adherence.

\section{Method Overview}

The strategy followed in this study included the following steps: (1) initial development of intervention content and conversion into an electronic format, (2) preliminary testing of the intervention's content, usability, and acceptability to likely users, and (3) assessing the effect of the intervention on participants' information, motivation, and behavioral skills as well as their medication adherence.

\section{Initial development}

Content for the intervention was initially developed through a survey of existing patient education materials with review by a multidisciplinary team that included representatives from medicine, nursing, psychology, pharmacy, and social work. 
The content was organized into sections that focused on basic HIV-related information (viral life cycle and mechanism of action of medications), factors and possible barriers related to motivation (misconceptions about medications and strategies for coping with stigma, depression, and substance abuse), and behavioral skills (strategies to remember to take medications). The content was presented in an interactive and tailored format, with automated responses using the participant's name. After presentation of specific information elements, participants were asked to respond to multiple choice questions about the information presented. If they responded correctly, the intervention moved on to the next element; if not, the material was presented again.

Content targeting barriers to adherence included material on coping and obtaining help with depression and substance abuse and counteracting common misconceptions about medications such as the desirability of avoiding medications after drinking alcoholic beverages ${ }^{20}$ Content intended to assist participants in developing behavioral skills included the presentation of several strategies for sustained medication adherence such as the use of reminders, scheduling medications together with other daily activities such as meals, and enlisting social support. Given the increasing evidence for the importance of health numeracy in general and the authors' own research on the importance of numeracy for adherence, ${ }^{21}$ some content specifically focused on translating numeric concepts into easily understood formats. Specific content was translated into a multimedia format supported by pictures, diagrams, and a brief animation of the viral life cycle.

The intervention was created using a widely available software program, Adobe ${ }^{\circledR}$ Captivate $^{\circledR}$ (Version 4, Adobe Corporation, San Jose, CA). This software provides designers the ability to create a multimedia program with graphic and video elements that can be output in a format (Flash ${ }^{\circledR}$ Player; Adobe) that plays on most computers. The program allows the designer to include multiple choice questions that enhance participant learning, and the program can branch to different content based on participant responses. It was thus possible to assess participant learning in an ongoing fashion and provide review of the content for participants who did not demonstrate mastery. The approximately 1-hour long intervention was delivered on stock touch screen computers $\left(\mathrm{HP}^{\circledR}\right.$ TouchSmart series; Hewlett-Packard Company, Palo Alto, CA). All text was recorded and provided to participants over built-in speakers from the computer. Development costs were kept to a minimum by using low-cost or open-source media.

\section{Usability and acceptability}

The content and format of the intervention was initially assessed by observing an initial group of five potential users of the intervention as they interacted with it and were asked to "think out loud" as they did so. Following this observation, participants were debriefed about the intervention content and its usability. After completing this process with five participants, the content and navigation of the scheme of the intervention was revised and tested with a second group of five potential users. Content changes over the course of pilot testing included changes in emphasis on the use of religious services for mental health services and a reduction in complexity of the explanations of medication effects. Navigation element changes included the addition of a "back" button allowing the user to review previous screens. Only minor revisions were required after the second group, and the study proceeded.

\section{Assessment of intervention effects}

The intervention was administered using stock touch screen computers (HP TouchSmart 300; Hewlett-Packard) with a 20-inch (diagonal) screen that required minimal computer skills to use - participants could respond to assessment questions simply by touching the correct answer on the computer screen.

\section{Participants}

Participants were recruited from the local practices of physicians treating persons with HIV infection and through participants' referral of other persons treated for HIV infection in Broward County, FL, including the city of Fort Lauderdale. The county is primarily urban and suburban. The county has a total population of $1,780,000$ which is $67 \%$ white and $27 \%$ black, and $12 \%$ of its residents have incomes that are within the United States government's definition of poverty. $^{22}$ More than 16,000 persons in the area are living with HIV/acquired immunodeficiency syndrome, of whom $71 \%$ are men and $29 \%$ women, and $50 \%$ are black and $34 \%$ white. $^{23}$

\section{Measures}

Because a number of studies have shown that cognitive abilities including health literacy are important predictors of medication adherence, ${ }^{24-26}$ participants' cognitive status was assessed with a battery of measures. The measures that comprise the assessment battery for this study were selected to assess health literacy using the full-length version of the Test of Functional Health Literacy in Adults (TOFHLA). ${ }^{27}$ 
TOFHLA is a measure of a person's ability to understand written passages of health care-related text (reading subscale) and to understand and apply quantitative data information related to medication taking, laboratory values, and health finance (numeracy subscale). The battery also included a measure of executive function using the Trail Making Test, Parts A and B. ${ }^{28}$ This measure requires the person assessed to rapidly draw a line with a pencil between numbers (Trails A) and alternative numbers and letters (Trails B). While Trails A is often interpreted as a measure of psychomotor speed, Trails B requires attention, memory, and mental switching.

Memory was assessed with the immediate and delayed recall trials of the Logical Memory subtest of the Wechsler Memory Scale - Fourth Edition. ${ }^{29}$ This measure requires participants to attend to and remember the elements of two brief stories. Participants are asked to remember the elements immediately after hearing the stories in the immediate recall trial and after 20 minutes in the delayed recall trial. Scores for this measure are normalized on a large national sample and have a mean value of ten and a standard deviation of three.

The LifeWindows IMB scale, a self-report measure of participants' understanding of the elements of the IMB model, was included in order to assess the intervention's effects on the elements of the model. ${ }^{30}$ It yields a subscale score for each of the elements of the IMB model. The Adult Acquired Immunodeficiency Syndrome Clinical Trials Group baseline adherence questionnaire was included during the first study visit. ${ }^{31}$ All rating scale measures were administered via audio computer-assisted self-interview using the Questionnaire Development System (QDS ${ }^{\mathrm{TM}}$, QDS Version 2.6; Nova Research Company, Bethesda, MD).

\section{Medication adherence}

Participants' medication adherence was assessed using the Medication Event Monitoring System (MEMSTM; Aardex Group Ltd, Sion, Switzerland). MEMS includes a device that electronically records each time a target medication's pill bottle is opened, serving as a measure of how the participant took his or her medication. The information is read into a computer and a program provides a measure of the extent to which the participant took his or her medication each day during the period observed. In this study, the MEMS index calculated by the number of correct doses taken during each 24-hour period was used as the index of adherence. This strategy takes into account the importance of the correct timing of doses for viral suppression. ${ }^{32,33}$

These included an assessment of health literacy using the full-length version of TOFHLA, ${ }^{27}$ executive function using the Trails A and Trails $\mathrm{B},{ }^{28}$ and memory using the immediate and delayed recall trials of the Logical Memory subtest of the Wechsler Memory Scale - Fourth Edition. ${ }^{29}$ A subset of these measures was used in the statistical analyses reported here.

\section{Procedure}

Evaluation of the intervention's effects was completed over three visits at 1-month intervals. At the first visit, participants completed initial assessments that included the cognitive battery and were instructed in how to use the MEMS pill bottles. Participants were seen on a second occasion 1 month later when their baseline adherence was recorded and they completed the electronic intervention. Participants were then seen on a third occasion during which their post-intervention medication adherence was recorded.

\section{Data analyses}

All data were collected by the senior author or his research assistant and analyzed by the senior author. The effectiveness of the intervention was evaluated in a pre-post design using repeated measures analysis of covariance (ANCOVA) models. Models corrected for participants' demographic characteristics (age, gender, race, and education), cognitive abilities (memory, executive function, and health literacy), and treatment variables (years of treatment and number of HIV medications). Changes in adherence were evaluated over two data points (for the months immediately before and after the participant completed the intervention). A substantial number of participants had high levels of adherence at baseline as measured by MEMS (greater than 90\%), suggesting that analyses might be complicated by the presence of ceiling effects in adherence since participants who already had high levels of adherence could not increase their level of adherence very much in response to the intervention. Change in adherence was therefore explored for subgroups of participants with lower levels of adherence (less than 95\%, less than $90 \%$, less than $85 \%$, and less than $80 \%$ ). Model-corrected predicted levels of adherence before and after the intervention were calculated for each subgroup to assess their degree of response to the intervention.

Changes in participants' self-reported information, motivation, and behavioral skills were assessed in repeated measures ANCOVA models for each subscale of the LifeWindows questionnaire. The impact of changes in information, motivation, and behavioral skills on participants' medication adherence was assessed in a regression model that corrected for demographic variables, baseline levels of health literacy and general cognitive ability, and memory. 
The study was completed under a protocol approved by the Nova Southeastern University Institutional Review Board (Fort Lauderdale, FL). Written informed consent was obtained from all participants prior to their entry into the study.

\section{Results}

Data collection and study visits began in May 2010 and continued until December 2011. There were 124 participants enrolled in the study who completed the first visit. Of these, 120 returned for the second visit during which they completed the intervention. Reasons for the four participants not returning for the second visit were: withdrawing consent due to illness and the time demands of the study (one participant), loss to follow-up in spite of multiple attempts to contact (one), and incarceration (two). Complete data for statistical analysis were available for 109 participants. Missing data resulted from some participants' difficulty in completing some measures (eg, not responding to an item) and to the loss of two participants between the intervention study visit and follow-up. One person moved from the area, and another was incarcerated.

Descriptive statistics for the sample of participants who completed the intervention are presented in Table 1 (risk factors for infection [Table 1A] and education [Table 1B]), Table 2 (continuous variables describing participants), and Table 3 (continuous variables for measures used in the study). Participants reported a wide range of educational backgrounds and included both heterosexual and homosexual sex as risk factors for infection as well as substance use and transfusions. They also had a wide range of experiences with treatment, ranging from a few months to several years, and a range of regimen complexities. Medications monitored in evaluation of each participant's level of adherence (chosen according to most frequent dosing or highest likelihood of

Table IA Description of sample for categorical variables: selfreport of how infection occurred

\begin{tabular}{lllll}
\hline $\begin{array}{l}\text { How participant became } \\
\text { infected (self-report) }\end{array}$ & $\begin{array}{l}\text { Men } \\
\mathbf{n = 8 8}\end{array}$ & $\begin{array}{l}\text { Women } \\
\mathbf{n = 3 6}\end{array}$ & $\begin{array}{l}\text { Blacks } \\
\mathbf{n = 7 8}\end{array}$ & $\begin{array}{l}\text { Whites } \\
\mathbf{n = 4 5}\end{array}$ \\
\hline Sex with man & $47(53 \%)$ & $29(81 \%)$ & $38(49 \%)$ & $38(84 \%)$ \\
Sex with woman & $37(42 \%)$ & $6(17 \%)^{\ddagger}$ & $37(47 \%)$ & $6(13 \%)$ \\
Shared needles & $16(18 \%)$ & $4(11 \%)$ & $10(13 \%)$ & $10(22 \%)$ \\
Transfusion & $9(10 \%)$ & $6(17 \%)$ & $12(15 \%)$ & $3(7 \%)$ \\
Other & $9(10 \%)$ & $2(6 \%)$ & $7(9 \%)$ & $4(9 \%)$ \\
Don't know & $21(24 \%)$ & $11(31 \%)$ & $29(37 \%)$ & $3(7 \%)$ \\
Totals $^{\dagger}$ & 139 & 58 & 133 & 64 \\
\hline
\end{tabular}

Notes: ${ }^{\dagger}$ Exceed sample size due to several participants indicating multiple risk factors; ₹of the women reporting sex with another woman as a risk factor, only one did not report another risk factor, such as sex with a man or sharing needles.
Table IB Description of sample for categorical variables: education

\begin{tabular}{lllll}
\hline Education & Men & Women $^{\dagger}$ & Blacks & Whites $^{\ddagger}$ \\
\hline I Ith grade or less & $29(33 \%)$ & $17(47 \%)$ & $42(54 \%)$ & $4(9 \%)$ \\
High school or GED & $30(34 \%)$ & $15(42 \%)$ & $24(31 \%)$ & $21(47 \%)$ \\
$\begin{array}{l}\text { 2-year college/AA/ } \\
\text { technical college }\end{array}$ & $17(19 \%)$ & $1(3 \%)$ & $7(9 \%)$ & $11(24 \%)$ \\
College graduate & $9(10 \%)$ & $2(6 \%)$ & $3(4 \%)$ & $8(18 \%)$ \\
Master degree or greater & $2(2 \%)$ & $0(0 \%)$ & I (1\%) & I (2\%) \\
\hline
\end{tabular}

Notes: ${ }^{\dagger}$ Test of the association of gender and educational status: $\chi^{2}=8.12$ (degrees of freedom $=4), P=0.09$; "test of the association of race and educational status: $\chi^{2}=28.31$ (degrees of freedom $=4$ ), $P<0.001$.

Abbreviations: AA, Associate in Arts; GED, General Educational Development.

side effects) were protease inhibitors (62 participants; 52\%) combination medications (34 participants; 28\%), integrase inhibitor (13 participants; 11\%), non-nucleoside reverse transcriptase inhibitor (eight participants; 7\%), and nucleoside reverse transcriptase inhibitor (three participants; 3\%). Women and blacks reported lower levels of educational attainment, although only the relation of women to lower levels of education approached conventional levels of statistical significance. White men were more likely to report having sex with another man as a risk factor, while blacks in the sample reported lower levels of educational attainment.

Participants' levels of health literacy can be interpreted according to cutoff values provided for the TOFHLA by its authors, ${ }^{27}$ with a total score less than 59 representing "inadequate" health literacy, scores in the range from 60-74 "marginal," and greater than 75 "adequate" health literacy. In this sample, six participants had inadequate, ten marginal, and 108 had adequate levels of health literacy. It can be seen that the average score on the measure was in the adequate range, although the range of scores shows that a wide range of health literacy was present in the sample. A histogram of participants' baseline levels of adherence is presented in Figure 1.

Results of the repeated measures ANCOVA model for participants with less than $95 \%$ baseline adherence are

Table 2 Description of sample for continuous variables

\begin{tabular}{llllll}
\hline & $\mathbf{n}$ & Minimum & Maximum & Mean & SD \\
\hline Age & 124 & 20 & 67.00 & 47.10 & 8.69 \\
CD4 & 124 & 62 & 1734.00 & 501.23 & 289.29 \\
Viral load & 124 & $0^{\dagger}$ & $2,321,000$ & 23,000 & 21,000 \\
$\begin{array}{l}\text { Years since first } \\
\text { treatment }\end{array}$ & 123 & 0.25 & 24.00 & 11.60 & 7.18 \\
$\begin{array}{l}\text { HIV meds doses } \\
\text { per day }\end{array}$ & 124 & 1 & 8.00 & 2.83 & 1.50 \\
\hline
\end{tabular}

Note: 'Zero for this variable represents a laboratory report of "nondetectable." Abbreviations: CD4, cluster of differentiation-4; HIV, human immunodeficiency virus; SD, standard deviation. 
Table 3 Description of sample for cognitive measures

\begin{tabular}{llllll}
\hline Measure & $\mathbf{n}$ & Minimum & Maximum & Mean & SD \\
\hline TOFHLA numeracy & 124 & 5 & 50 & 46.02 & 7.07 \\
TOFHLA reading & 124 & 13 & 50 & 42.46 & 8.50 \\
TOFHLA total score & 124 & 20 & 100 & 88.48 & 14.16 \\
WMS-IV immediate & 124 & 1 & 15 & 7.56 & 3.27 \\
WMS-IV delayed & 124 & 1 & 15 & 7.60 & 3.05 \\
MEMS correct (\%) & 118 & 6.9 & 100 & 81.46 & 20.95
\end{tabular}

Abbreviations: MEMS, Medication Event Monitoring System; SD, standard deviation; TOFHLA, Test of Functional Health Literacy in Adults; WMS-IV, Wechsler Memory Scale - Fourth Edition.

summarized in Table 4. This analysis showed a significant effect for time before and after the intervention, although the change in adherence for this group was small $(2.3 \%$; Figure 2). The same model was evaluated for subgroups of participants based on progressively lower levels of baseline adherence cutoffs (less than $90 \%$ to less than $70 \%$ at $5 \%$ intervals). Table 4 also presents a significant effect of time by TOFHLA numeracy. Evaluation of the direction of the relationship through graphing (not presented) showed that participants with lower levels of numeracy showed greater increases in adherence after completing the intervention than did those with higher levels.

Results for the effect of time only for each subgroup are reported in Table 5. As the sample size with which each model was calculated became progressively smaller and thus had limited power to detect a statistically significant effect, the effect size for each model was also calculated and is reported. Analyses of pre-post differences for the entire group did not result in a statistically significant effect for time and showed a small effect size. For subgroups with lower levels of baseline adherence, however, the intervention was associated with

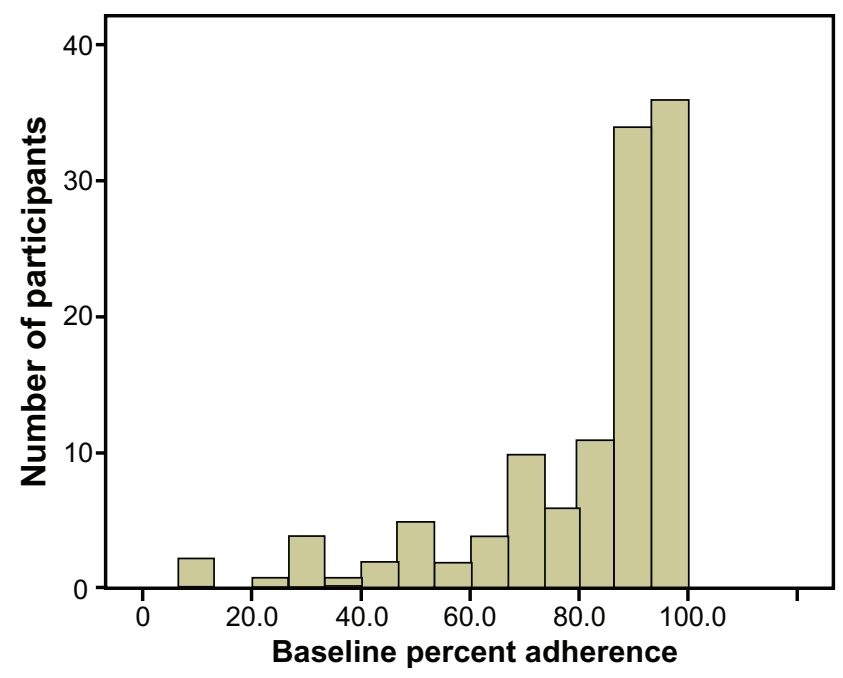

Figure I Histogram of participants' baseline adherence.
Table 4 Model for time and covariates for participants with less than $95 \%$ baseline adherence

\begin{tabular}{|c|c|c|c|c|c|}
\hline Source & $\begin{array}{l}\text { Sum of } \\
\text { squares }\end{array}$ & df & $\begin{array}{l}\text { Mean } \\
\text { square }\end{array}$ & $\mathbf{F}$ & $P$ \\
\hline Time & 1940.93 & 1 & 1940.93 & 7.08 & 0.01 \\
\hline Time $\times$ gender $^{\dagger}$ & 527.10 & 1 & 527.10 & 1.92 & 0.17 \\
\hline Time $\times$ race $^{\ddagger}$ & 196.97 & I & 196.97 & 0.72 & 0.40 \\
\hline Time $\times$ age & 34.19 & 1 & 34.19 & 0.12 & 0.73 \\
\hline Time $\times$ education & 244.33 & 1 & 244.33 & 0.89 & 0.35 \\
\hline Time $\times$ Trails $B$ & 180.64 & I & 180.64 & 0.66 & 0.42 \\
\hline Time $\times$ delayed recall & 156.84 & 1 & 156.84 & 0.57 & 0.45 \\
\hline Time $\times$ immediate recall & 121.15 & 1 & 121.15 & 0.44 & 0.51 \\
\hline Time $\times$ years treated & 583.10 & 1 & 583.10 & 2.13 & 0.15 \\
\hline Time $\times$ medication doses & 68.36 & 1 & 68.36 & 0.25 & 0.62 \\
\hline Time $\times$ TOFHLA reading & 94.92 & 1 & 94.92 & 0.35 & 0.56 \\
\hline Time $\times$ TOFHLA numeracy & $13|2.4|$ & 1 & $|3| 2.4 \mid$ & 4.79 & 0.03 \\
\hline Error & $17,280.13$ & 63 & 274.29 & & \\
\hline
\end{tabular}

Notes: †Gender was coded "I" for men and "2" for women in these analyses; ${ }^{\ddagger}$ race was coded "I" for whites and " 2 " for blacks in these analyses.

Abbreviations: df, degrees of freedom; TOFHLA, Test of Functional Health Literacy in Adults; Trails B, Trail Making Test Part B.

increasingly larger changes in adherence. Effect size, however, was largest for the group with baseline adherence less than $85 \%$ (mean baseline adherence of $58 \%$; effect size of 0.17 , ie, a large effect size) ${ }^{34}$ Effect size depends not only on the magnitude of change observed but also the subsample's underlying variability; it is possible that the intervention was differentially effective for some participants in these groups. The relation of baseline adherence to change in adherence and to effect size of the intervention is illustrated in Figures 2 and 3 , respectively.

Repeated measures ANCOVA models for change over time in information, motivation, and behavioral skills (LifeWindows questionnaire subscales ${ }^{30}$ ) showed that participants' report of their knowledge and behavioral skills increased significantly over the course of the study (effect of time for

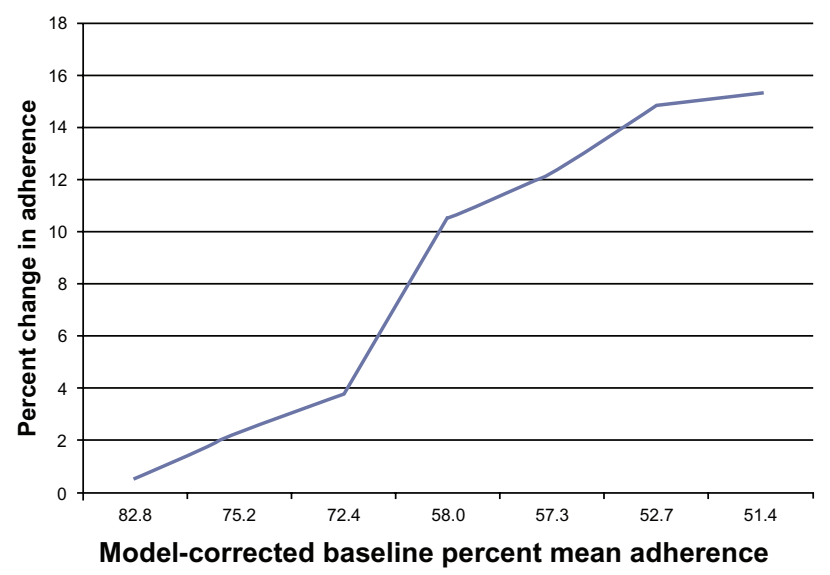

Figure 2 Change in adherence as a function of baseline adherence. 
Table 5 Pre-post tests for change in adherence across subgroups ${ }^{\dagger}$

\begin{tabular}{llllllll}
\hline $\begin{array}{l}\text { Baseline } \\
\text { adherence }\end{array}$ & $\mathbf{n}$ & $\begin{array}{l}\text { Sum of } \\
\text { squares }\end{array}$ & $\begin{array}{l}\text { df } \\
\text { Square }\end{array}$ & $\begin{array}{l}\text { Mean } \\
\text { square }\end{array}$ & $\mathbf{P}$ & $\eta^{2}$ \\
\hline Complete sample & 109 & 741.40 & $\mathrm{I}$ & 741.40 & 3.47 & 0.07 & 0.035 \\
$<95 \%$ & 75 & 1940.93 & $\mathrm{I}$ & 1940.93 & 7.08 & $0.0 \mathrm{I}^{\ddagger}$ & $0.10 \mathrm{I}$ \\
$<90 \%$ & 64 & 1835.57 & $\mathrm{I}$ & 1835.57 & 7.35 & 0.009 & 0.124 \\
$<85 \%$ & 36 & 1625.77 & $\mathrm{I}$ & 1625.44 & 4.69 & 0.04 & $0.17 \mathrm{I}$ \\
$<80 \%$ & 33 & 910.58 & $\mathrm{I}$ & 910.58 & 3.09 & 0.09 & 0.128 \\
$<75 \%$ & 27 & 678.16 & $\mathrm{I}$ & 678.16 & 1.79 & 0.20 & 0.106 \\
$<70 \%$ & 23 & 529.84 & $\mathrm{I}$ & 529.84 & 1.03 & 0.33 & 0.086
\end{tabular}

Notes: 'Because of progressively smaller sample sizes, effect sizes $\left(\eta^{2}\right)$ as well as statistical significances are reported, where $0.01=$ small, $0.06=$ medium, and $0.14=$ large effect size, ${ }^{35}$ ffull model reported in Table 4.

information $\mathrm{F}[2,96]=4.25, P=0.02$ and effect of time for behavioral skills $\mathrm{F}[2,96]=4.17 ; P=0.02)$. The effect of time for motivation was not significant (effect of time $\mathrm{F}$ $[2,96]=0.67 ; P=0.51)$. Regression models evaluating the impact of changes in information, motivation, and behavioral skills on participants' medication adherence showed that change in information over the course of the study was a significant predictor of medication adherence at the final study visit $\left(\chi^{2}=7.35\right.$; degrees of freedom $\left.=1 ; P=0.001\right)$. Models evaluating the impact of change in motivation and behavioral skills showed that they were not significant predictors of adherence $(P>0.10)$.

\section{Discussion}

The purpose of these analyses was to evaluate the relation of baseline levels of medication adherence on participants' response to an electronically delivered intervention that targeted patients' health literacy as a way of improving their medication adherence. Results suggest that there is a relationship between baseline adherence and response to the intervention, with those with lower baseline levels of adherence showing the largest changes after the intervention.

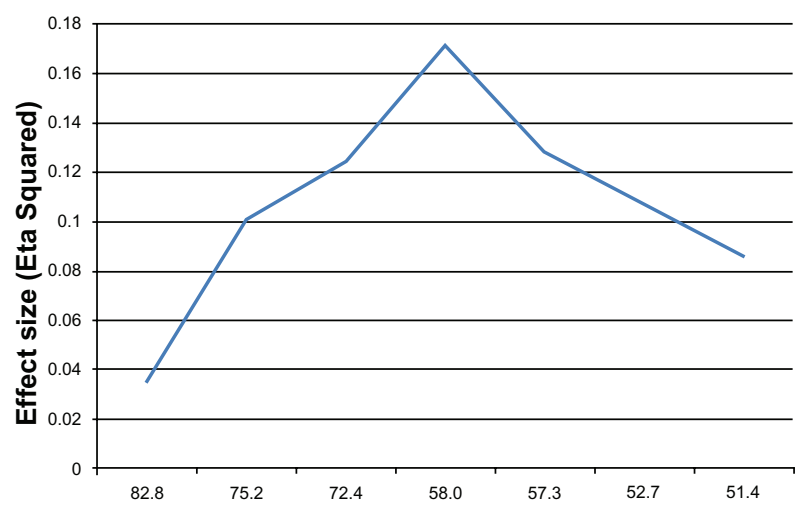

Model-corrected baseline percent mean adherence

Figure 3 Intervention size as a function of baseline adherence.
Observed effect sizes for the intervention mirrored in part these findings, with the intervention resulting in large effect sizes for those with lower levels of adherence up to $58 \%$, but then showed decreasing effect sizes. ${ }^{34}$ The smaller change observed in participants with higher levels of adherence can be attributed to a ceiling effect, since participants with high levels of adherence at baseline could not increase their adherence by a large amount. Participants with $95 \%$ baseline adherence, for example, could only increase their adherence by a maximum of $5 \%$, while those with levels of adherence less than $70 \%$ could increase their adherence by substantially greater amounts. The finding of decreased effect sizes for those with the lowest levels of adherence may be related to increased variability in the subsamples as effect size depends not only on change but also on underlying variability. There may be many reasons for persons to have low levels of adherence, such as lack of financial resources, that could not be addressed by the computer intervention. Finally, in other analyses it was shown that participants' self-report of HIVrelated knowledge and behavioral skills increased over the course of the study, and their change in information predicted their post-intervention medication adherence.

Several of the models presented in Table 5 did not result in a statistically significant change in adherence over time. For analysis of the entire sample, this can be interpreted as the result of including a number of persons with high levels of adherence. For analyses of subgroups with lower levels of baseline adherence, the failure to find a statistically significant effect for time may be the result of the reduced sample size associated with these analyses.

Limitations of this report include the post hoc nature of the analyses, the lack of a control group for comparisons of the intervention's effects, and the need to account for a large number of cognitive covariates in analyses of treatment effects. Analyses of subgroups selected after initial study design are associated with the risk of spurious findings of statistical significance. In these analyses, resolving this problem was attempted by examining the data for a pattern in findings across the subgroups. As illustrated in Figure 2, a relationship between baseline adherence and change in adherence in response to the intervention appears consistent across subgroups, even though tests of the effect are statistically significant only for some subgroups.

Another limitation is the research design employed that did not include a control group. The design of the study, intentionally created as an exploratory investigation of the intervention's potential effects, precluded the incorporation of a control group. Because of this design, the possibility 
that the effects of the intervention observed in these analyses were simply the result of participants' inclusion in the study cannot be excluded. It is possible that simply participating in the study resulted in increases in adherence, although it should be noted that observed changes in adherence occurred between the participants' entry into the study and their exposure to the intervention. This issue was addressed in analyses that assessed changes in participants' information, motivation, and behavioral skills across the course of the study and the relation of changes to participants' ultimate medication adherence. These results showed that participants' information and behavioral skills increased significantly over the course of the study, and that changes in information predicted their medication adherence at the study's conclusion. This suggests that participants' response to the intervention rather than the general effects of study participation was related to their adherence. A more definitive evaluation of the effects of the study intervention depends on further evaluation in more a rigorous study design.

ANCOVA models reported here include a substantial number of covariates. The inclusion of covariates in ANCOVA models increases statistical power by allowing a more precise determination of the intervention's effects by accounting for external influences that might affect participants' responses. In the models reported here, the effects of standard demographic variables shown in other studies to have an effect on adherence were taken into account (gender, race, age, and education). In order to evaluate participants' response to the intervention, the effects of memory were also considered important. Finally, as the intervention was targeted at improving participants' health literacy, their baseline level of health literacy was also taken into account in evaluating their response to the intervention. It can be noted that in the model for participants with less than 95\% adherence, an interaction between baseline health numeracy and change in adherence over time was observed (Table 4). Examination of the interaction showed that participants with lower baseline scores on numeracy showed greater changes in adherence from first to second assessments of their adherence. A particular focus of the intervention development was an attempt to communicate numeric data to participants in ways that could be easily understood. This was done by presenting numeric data on the meaning of $95 \%$ adherence in a graphic format (a calendar) that illustrated precisely how many doses a month the patient could miss and still have 95\% adherence. Several participants commented during the study that this was helpful to them. The finding of the interaction suggests that the effort to communicate the precise meaning of high levels of adherence in clear behavioral terms may have been helpful.

Other studies of electronic interventions have shown that they can have positive impact on patients' health. A study that evaluated the efficacy of computer cognitive behavioral therapy for depression showed that it was effective. ${ }^{35}$ A computer-based application that focused on smoking cessation in primary care patients was also effective. ${ }^{36}$ Other electronic interventions, including those delivered by telephone or text messaging, have been effective in improving medication adherence. ${ }^{37}$

\section{Conclusion}

Results of this study thus show that an electronically delivered intervention designed to improve patients' health literacy may have an effect on participants' medication adherence. Analyses of subgroups across baseline levels of adherence further suggest that participants with lower levels of adherence may show a larger response to the intervention. Electronic interventions for adherence may be a useful strategy to provide an adherence intervention.

\section{Acknowledgments}

Support for this study was provided by grant R21MH086491 to Dr Ownby from the National Institute of Mental Health.

\section{Disclosure}

The authors report no conflicts of interest in this work.

\section{References}

1. Bangsberg DR, Kroetz DL, Deeks SG. Adherence-resistance relationships to combination HIV antiretroviral therapy. Curr HIV/AIDS Rep. 2007;4(2):65-72.

2. Bangsberg DR. Less than $95 \%$ adherence to nonnucleoside reversetranscriptase inhibitor therapy can lead to viral suppression. Clin Infect Dis. 2006;43(7):939-941.

3. Maggiolo F, Ravasio L, Ripamonti D, et al. Similar adherence rates favor different virologic outcomes for patients treated with nonnucleoside analogues or protease inhibitors. Clin Infect Dis. 2005;40(1):158-163.

4. Nieuwkerk PT, Sprangers MA, Burger DM, et al. Limited patient adherence to highly active antiretroviral therapy for HIV-1 infection in an observational cohort study. Arch Intern Med. 2001;161(6):1962-1968.

5. Tesoriero J, French T, Weiss L, Waters M, Finkelstein R, Agins B. Stability of adherence to highly active antiretroviral therapy over time among clients enrolled in the treatment adherence demonstration project. J Acquir Immune Defic Syndr. 2003;33(4):484-493.

6. Knobel H, Guelar A, Carmona A, et al. Virologic outcome and predictors of virologic failure of highly active antiretroviral therapy containing protease inhibitors. AIDS Patient Care STDS. 2001;15(4):193-199.

7. Garcia de Olalla P, Knobel H, Carmona A, Guelar A, Lopez-Colomes JL, Cayla JA. Impact of adherence and highly active antiretroviral therapy on survival in HIV-infected patients. J Acquir Immune Defic Syndr. 2002;30(1):105-110.

8. Cohen MS, Chen YQ, McCauley M, et al. Prevention of HIV-1 infection with early antiretroviral therapy. $N$ Engl J Med. 2011;365(6):493-505. 
9. Fisher JD, Fisher WA, Amico KR, Harman JJ. An informationmotivation-behavioral skills model of adherence to antiretroviral therapy. Health Psychol. 2006;25(4):462-473.

10. Janz NK, Becker MH. The Health Belief Model: a decade later. Health Educ Q. 1984;11(1):1-47.

11. Ajzen I. The theory of planned behavior. In: Van Lange PAM, Kruglanski AW, Higgins ET, editors. Handbook of Theories of Social Psychology. London: Sage Publications; 2012:438-459.

12. Simoni JM, Pearson CR, Pantalone DW, Marks G, Crepaz N. Efficacy of interventions in improving highly active antiretroviral therapy adherence and HIV-1 RNA viral load. A meta-analytic review of randomized controlled trials. J Acquir Immune Defic Syndr. 2006;43(Suppl 1): S23-S35.

13. Simoni JM, Amico KR, Pearson CR, Malow R. Strategies for promoting adherence to antiretroviral therapy: a review of the literature. Curr Infect Dis Rep. 2008;10(6):515-521.

14. Safren SA, O'Cleirigh C, Tan JY, et al. A randomized controlled trial of cognitive behavioral therapy for adherence and depression (CBT-AD) in HIV-infected individuals. Health Psychol. 2009;28(1):1-10.

15. Osterberg L, Blaschke T. Adherence to medication. $N$ Engl J Med. 2005;353(5):487-497.

16. Kalichman SC, Rompa D. Functional health literacy is associated with health status and health-related knowledge in people living with HIVAIDS. J Acquir Immune Defic Syndr. 2000;25(4):337-344.

17. Kalichman SC, Benotsch E, Suarez T, Catz S, Miller J, Rompa D. Health literacy and health-related knowledge among persons living with HIV/ AIDS. Am J Prev Med. 2000;18(4):325-331.

18. Kalichman SC, Ramachandran B, Catz S. Adherence to combination antiretroviral therapies in HIV patients of low health literacy. $J$ Gen Intern Med. 1999;14(5):267-273.

19. Nielsen-Bohlman L, Panzer AM, Hamlin B, Kindig DA, editors. Health Literacy: A Prescription to End Confusion. Washington, DC: National Academies Press; 2004.

20. Kalichman SC, Amaral CM, White D, et al. Alcohol and adherence to antiretroviral medications: interactive toxicity beliefs among people living with HIV. J Assoc Nurses AIDS Care. March 14, 2012. [Epub ahead of print.]

21. Waldrop-Valverde D, Osborn CY, Rodriguez A, Rothman RL, Kumar M, Jones DL. Numeracy skills explain racial differences in HIV medication management. AIDS Behav. 2010;14(4):799-806.

22. United States Census Bureau. State and county QuickFacts: Broward County, Florida. Updated August 16, 2012. Available from: http:// quickfacts.census.gov/qfd/states/12/12011.html. Accessed September 9, 2012.

23. Broward County Health Department. HIV/AIDS surveillance report through December 31, 2011. 2012. Available from: http://browardchd. org/LinkClick.aspx?fileticket=n5ihDbupLPE\%3d\&tabid=104. Accessed September 9, 2012.
24. Hinkin CH, Castellon SA, Durvasula RS, et al. Medication adherence among HIV+ adults: effects of cognitive dysfunction and regimen complexity. Neurology. 2002;59(12):1944-1950.

25. Kalichman SC, Pope H, White D, et al. Association between health literacy and HIV treatment adherence: further evidence from objectively measured medication adherence. J Int Assoc Physicians AIDS Care (Chic). 2008;7(6):317-323.

26. Lovejoy TI, Suhr JA. The relationship between neuropsychological functioning and HAART adherence in HIV-positive adults: a systematic review. J Behav Med. 2009;32(5):389-405.

27. Parker RM, Baker DW, Williams MV, Nurss JR. The test of functional health literacy in adults: a new instrument for measuring patients' literacy skills. J Gen Intern Med. 1995;10(10):537-541.

28. Lezak M, Howieson DB, Loring DW. Neuropsychological Assessment. 4th ed. New York, NY: Oxford University Press; 2004.

29. Wechsler D. Wechsler Memory Scale - Fourth Edition (WMS-IV). San Antonio, TX: Pearson Clinical Assessment; 2009.

30. The LifeWindows Project Team. The LifeWindows InformationMotivation-Behavioral Skills ART Adherence Questionnaire (LW-IMB$A A Q)$. Storrs, CT: Center for Health, Intervention, and Prevention at the University of Connecticut; 2006.

31. Chesney MA, Ickovics JR, Chambers DB, et al. Self-reported adherence to antiretroviral medications among participants in HIV clinical trials: the AACTG adherence instruments. Patient Care Committee and Adherence Working Group of the Outcomes Committee of the Adult AIDS Clinical Trials Group (AACTG). AIDS Care. 2000;12(3): 255-266.

32. Gill CJ, Sabin LL, Hamer DH, et al. Importance of dose timing to achieving undetectable viral loads. AIDS Behav. 2010;14(4):785-793.

33. Sabin LL, DeSilva MB, Hamer DH, et al. Using electronic drug monitor feedback to improve adherence to antiretroviral therapy among HIVpositive patients in China. AIDS Behav. 2010;14(3):580-589.

34. Cohen J. Statistical Power Analysis for the Behavioral Sciences. 2nd ed. New York, NY: Routledge Academic; 1988.

35. McCrone P, Knapp M, Proudfoot J, et al. Cost-effectiveness of computerised cognitive-behavioural therapy for anxiety and depression in primary care: randomised controlled trial. Br J Psychiatry. 2004;185:55-62.

36. Smith MY, Cromwell J, DePue J, Spring B, Redd W, Unrod M. Determining the cost-effectiveness of a computer-based smoking cessation intervention in primary care. Manag Care. 2007;16(7):48-55.

37. Heckman TG, Carlson B. A randomized clinical trial of two telephonedelivered, mental health interventions for HIV-infected persons in rural areas of the United States. AIDS Behav. 2007;11(1):5-14.
Neurobehavioral HIV Medicine

\section{Publish your work in this journal}

Neurobehavioral HIV Medicine is an international, peer-reviewed, open access journal focusing on advances in research in HIV/ AIDS, with specific reference to the neurological, psychiatric and behavioral consequences of the disease, concomitant infections and specific antiretroviral therapy. The manuscript

\section{Dovepress}

management system is completely online and includes a very quick and fair peer-review system, which is all easy to use Visit http://www.dovepress.com/testimonials.php to read real quotes from published authors. 